\title{
Retraction Note: Coastal biometric recognition based on virtual sensor network and accounting cost accounting of logistics companies
}

\author{
Xincai Zhu ${ }^{1} \cdot$ Ying Jiang $^{1}$
}

Published online: 9 November 2021

(c) Saudi Society for Geosciences 2021

Retraction Note: Arabian Journal of Geosciences (2021) 14: 1771 https://doi.org/10.1007/s12517-021-08126-8

The Editor-in-Chief and the Publisher have retracted this article because the content of this article is nonsensical. The peer review process was not carried out in accordance with the Publisher's peer review policy. The authors have not responded to correspondence regarding this retraction.

The original article can be found online at https://doi.org/10.1007/ s12517-021-08126-8.

Xincai Zhu

zhuxincai2021@126.com

1 School of Economics \& Management, Yancheng Institute of Technology, Yancheng 224051, Jiangsu, China 